\title{
Intervenção em Adesão Baseada na Abordagem Construcionista do Cuidado: Perspectiva dos Profissionais de Saúde
}

\author{
Maria Altenfelder Santos ${ }^{1}$ \\ Maria Ines Battistella Nemes \\ Ana Cristina Arantes Nasser \\ Departamento de Medicina Preventiva da Universidade de São Paulo, São Paulo, Brasil \\ Cáritas Relva Basso \\ Departamento de Medicina Preventiva da Universidade de São Paulo, São Paulo, Brasil \\ Centro de Referência e Treinamento de DST e Aids da Secretaria de Estado da Saúde \\ de São Paulo, São Paulo, Brasil \\ Vera Silvia Facciolla Paiva \\ Departamento de Psicologia Social e do Trabalho da Universidade de São Paulo,
}

São Paulo, Brasil

\begin{abstract}
Resumo
Com base na noção de Cuidado, na perspectiva construcionista e no quadro da vulnerabilidade e dos direitos humanos, foi construída uma intervenção psicossocial individual voltada para a melhoria da adesão ao tratamento antirretroviral. A intervenção foi testada em uma pesquisa realizada em serviço de referência em DST/Aids de São Paulo, conduzida por três profissionais de saúde, previamente capacitadas. Com o objetivo de compreender a factibilidade da intervenção, as três profissionais foram entrevistadas, individualmente e em grupo. Foram descritos e discutidos os conteúdos abordados pelas profissionais, em relação aos seguintes temas: atividades de capacitação e supervisão; condução da intervenção; repercussões para a prática profissional e para o tratamento dos usuários; e implantação futura da intervenção. As entrevistadas relataram que a intervenção estimulou a reflexão sobre suas práticas de cuidado em HIV/Aids, levando-as à maior valorização da singularidade dos usuários e ao aprofundamento da conversa em torno de aspectos da vida cotidiana relacionados ao tratamento. Consideraram que a relação dialógica e horizontal estabelecida na intervenção promoveu maior participação dos usuários na escolha de caminhos para seu autocuidado. Descreveram que as principais dificuldades foram
\end{abstract}

Endereço para correspondência: Departamento de Medicina Preventiva, Faculdade de Medicina, Universidade de São Paulo, Av. Dr. Arnaldo, 455, Cerqueira César, $2^{\circ}$ andar, sala 2174, São Paulo, SP, Brasil 01246-903. Email: marialtenfelder@gmail.com,mibnemes@usp.br, anarantes.nasser@yahoo.com.br, cr_basso@terra.com. bre veroca@usp.br

Agradecimentos: Ao Centro de Referência e Treinamento em DST e AIDS da Secretária de Estado da Saúde de São Paulo, instituição onde a pesquisa foi realizada e, em especial, às profissionais de saúde participantes da pesquisa; à Fundação de Amparo à Pesquisa do Estado de São Paulo (FAPESP), pelo apoio financeiro aos projetos de pesquisa: "Avaliação de Tecnologias para Melhoria da Adesão do Paciente ao Tratamento Anti-retroviral da AIDS”, Chamada PP-SUS 2006/2007, FAPESP Processo No 2006/61277-6; e “Análise crítica de uma intervenção para melhoria da adesão do paciente vivendo com AIDS à terapia antirretroviral", FAPESP Processo No 2008/08007-6.

Dados parciais extraídos da dissertação de mestrado em Psicologia Social: Análise crítica de uma intervenção para melhoria da adesão do paciente vivendo com Aids à terapia antirretroviral / Maria Altenfelder Santos; orientadora: Vera Silvia Facciolla Paiva; coorientadora: Maria Ines Battistella Nemes. Instituto de Psicologia da Universidade de São Paulo, São Paulo, 2010. 
relacionadas à criação de vínculo com alguns usuários e destacaram a importância de as estratégias de intervenção fazerem sentido para a pessoa em tratamento, de acordo com seu momento e contexto de vida. Disseram acreditar na viabilidade da implantação futura da intervenção em outros serviços e apontaram para a necessidade de envolver os gestores e as diferentes categorias profissionais nesse processo.

Palavras-chave: Aids, intervenção psicossocial, direitos humanos, tratamento antirretroviral, adesão à medicação.

\title{
Adherence Intervention Based on Constructionist Care Approach: The Health Professionals' Perspective
}

\begin{abstract}
An individual psychosocial intervention geared to improve adherence to antiretroviral therapy. It was designed based on the concept of Care, on the constructionist perspective and on the vulnerability and human rights framework. This intervention was tested as part of a research project and was conducted by three previously trained health professionals in an STD/AIDS reference health facility in Sao Paulo. These three professionals were interviewed, both individually and as a group in order to assess the intervention's feasibility. We described and discussed the contents addressed by them regarding the following themes: training and supervision activities; intervention conducting; impact on professional practice and user care; and future intervention implementation. The interviewees reported that this intervention caused them to reflect on their previous practices regarding HIV healthcare. This promoted a better appreciation of the singularity of each user and also more substantial conversations about aspects of the users' daily life concerning their treatment. They considered that the dialogical and horizontal relationship established during the intervention increased users' participation regarding choices concerning paths to self-care. They reported that one of the main difficulties encountered was related to bonding with some users and highlighted the importance of the fact that the intervention strategies made sense to the people under treatment according to their life circumstances and context. They said they believed in the feasibility of future intervention implementation in other health facilities and also pointed the need to involve managers and different professionals during this process.
\end{abstract}

Keywords: AIDS, psychosocial intervention, human rights, antiretroviral therapy, medication adherence.

\section{Intervención en Adhesión Basada en el Abordaje Construccionista del Cuidado: Perspectiva de los Profesionales de Salud}

\section{Resumen}

Basado en la noción de Cuidado, en la perspectiva construccionista y en el cuadro de la vulnerabilidad y de los derechos humanos, fue construida una intervención psicosocial individual direccionada para la mejoría de la adhesión al tratamiento antirretroviral. La intervención fue testada en una investigación realizada en servicio de referencia en ITS/SIDA en São Paulo, conducida por tres profesionales de salud, previamente capacitadas. Con el objetivo de comprender la factibilidad de la intervención, las tres profesionales fueron entrevistadas, individualmente y en grupo. Fueron descritos y discutidos los contenidos abordados por las profesionales, en relación a los siguientes temas: actividades de capacitación y supervisión; conducción de la intervención; repercusión para la práctica profesional y para el tratamiento de los usuarios; e implantación futura de la intervención. Las entrevistadas relataron que la intervención estimuló la reflexión acerca de sus prácticas de cuidado en VIH/Sida, las llevando a mayor valoración de la singularidad de los usuarios y la profundización del diálogo acerca de aspectos de la vida cotidiana 
relacionados al tratamiento. Consideraron que la relación dialógica y horizontal establecida en la intervención promovió mayor participación de los usuarios en la elección de caminos para su autocuidado. Describieron que las principales dificultades fueron relacionadas a la creación de vínculo con algunos usuarios y destacaron la importancia de las estrategias de intervención hacer sentido para la persona en tratamiento, de acuerdo con su momento y contexto de vida. Dijeron creer en la viabilidad de la implantación futura de la intervención en otros servicios y apuntaron para la necesidad de involucraren los gestores y las diferentes categorías profesionales en ese proceso.

Palabras clave: SIDA, intervención psicosocial, derechos humanos, tratamiento antirretroviral, adhesión a la medicación.

A adesão da pessoa vivendo com HIV à terapia antirretroviral (TARV) é um aspecto fundamental de seu tratamento. A efetividade da TARV depende da manutenção de altas taxas de adesão das pessoas em tratamento aos esquemas terapêuticos prescritos - o que é essencial não apenas no âmbito do tratamento individual, mas também tem importante impacto na disseminação da doença no plano coletivo (Teixeira, Paiva, \& Shimma, 2000).

As investigações sobre essa questão, reconhecidamente complexa e multifacetada, desde a década de 1960 buscam medir as taxas de adesão em contextos diversos, utilizando estratégias metodológicas variadas, bem como explicar os porquês da não adesão (Caraciolo, 2010; Teixeira et al., 2000). A não adesão à TARV tem sido relacionada a duas dimensões: características da pessoa em tratamento (tais como perfil socioeconômico, uso de drogas, comorbidades); e características da doença e do tratamento em si (tais como tempo de tratamento, regime terapêutico, efeitos colaterais). Os estudos brasileiros também relacionam a adesão a características da organização da atenção nos serviços de saúde (tais como disponibilidade de recursos, acesso ao atendimento, tempo de duração das consultas, oferta de atividades voltadas para a melhoria da adesão; Teixeira et al., 2000). Destacam-se os estudos na última década que apontam para as relações entre a qualidade da assistência e as taxas de adesão ao tratamento da Aids entre pessoas em acompanhamento nos serviços de saúde (Nemes, 2009; Nemes, Castanheira, et al., 2009).

Não há consenso na literatura, entretanto, em torno das explicações sobre a efetividade das intervenções voltadas para a melhoria da adesão ao tratamento antirretroviral, assim como não há uma correspondência simples entre as estratégias utilizadas nas intervenções e as bases teóricas que as fundamentam (Amico, Harman, \& Johnson, 2006; Basso, 2010; Caraciolo, 2010; Dulmen et al., 2007; Munro, Lewin, Swart, \& Volmink, 2007; Rueda et al., 2006; Simoni, Frick, Pantalone, \& Turner, 2003; Simoni, Pearson, Pantalone, Marks, \& Crepaz, 2006).

Grande parte das intervenções para a melhoria da adesão à TARV está fundamentada em "modelos de mudança comportamental" (Bãban \& Crãciun, 2007) implicadas em teorias sobre comportamentos de saúde (health behaviors; Glanz, Lewis, \& Rimer, 2002). Destacam-se o Modelo de Crenças em Saúde; a Teoria da Ação Racional e do Comportamento Planejado; a Teoria Social Cognitiva; a Perspectiva Autorreguladora; o Modelo Transteórico; o Modelo de Estresse e Coping; a Perspectiva do Apoio Social; o Modelo da Comunicação Paciente-Profissional; e a Teoria da Informação, Motivação e Habilidades Comportamentais (Bãban \& Crãciun, 2007; Dulmen et al., 2007; Glanz et al., 2002; Munro et al., 2007).

Sem a pretensão de aprofundar a discussão desses modelos teóricos, ressaltamos seu enfoque na dimensão individual dos processos de adoecimento, com rara consideração aos contextos sociais, intersubjetivos e programáticos envolvidos no tratamento que os estudos epidemiológicos brasileiros têm ressaltado. Suas propostas de intervenção em adesão destinam-se predominantemente a: corrigir percepções ou crenças do paciente sobre adesão; modificar atitudes e comportamentos em relação ao tratamento; e treinar novas habilidades do paciente que facilitem a adesão (M. A. Santos, 2010). 
Este artigo discutirá uma proposta de intervenção, nomeada de "Abordagem Construcionista do Cuidado em Adesão" (ACCA), fundamentada em outro campo teórico: na noção de "Cuidado"2 (Ayres, 2001, 2004) e em uma abordagem psicossocial de inspiração construcionista (Paiva, 2012b), ambas desenvolvidas no quadro dos direitos humanos em saúde que tem distinguido a chamada "resposta brasileira à Aids" (Berkman, Garcia, Munoz-Laboy, Paiva, \& Parker, 2005; Gruskin \& Tarantola, 2008; Kalichman \& Diniz, 2009).

\section{O Quadro da Vulnerabilidade e dos Direitos Humanos (V\&DH): Referências para Prática em Saúde}

No campo da Aids, as referências que integram o chamado "quadro da vulnerabilidade e dos direitos humanos" têm consolidado nos últimos anos a análise da dinâmica da epidemia, que fundamenta a centralidade da garantia da não discriminação e, portanto, do acesso das pessoas vivendo com HIV à atenção à saúde de boa qualidade. Esse quadro conceitual emergiu no início dos anos 1990, marcando uma oposição às noções de grupos e comportamentos de risco, predominantes nas primeiras reações ao surgimento da epidemia, gerando a estigmatização de grupos e práticas (Mann \& Tarantola, 1996) ${ }^{3}$. Esse paradigma para pensar o processo saúde-doença buscava

[. . .] responder à percepção de que a chance de exposição das pessoas ao HIV e ao adoecimento pela Aids não é a resultante de um conjunto de aspectos apenas individu-

Cuidado grafado em maiúscula, de acordo com a proposta do autor.

3 Proposto inicialmente por um grupo de pesquisadores e ativistas, organizados na Universidade de Harvard e com forte presença no nascente programa de Aids das Nações Unidas (Joint United Nations Program on HIV/AIDS [UNAIDS]), o quadro da vulnerabilidade conseguiu se desenvolver mais fortemente no Brasil porque a resposta à epidemia foi paralela à formulação e construção do SUS, também fortemente inspiradas pela abordagem da saúde implicada na perspectiva dos direitos humanos (nas noções de igualdade, universalidade, integralidade e participação). ais, mas também coletivos, contextuais, que acarretam maior suscetibilidade à infecção e ao adoecimento, e, de modo inseparável, de maior ou menor disponibilidade de recursos de todas as ordens para se proteger (Ayres, Calazans, Saletti, \& França, 2006, p. 396).

Esse quadro está particularmente atrelado ao entendimento da saúde como um direito, assim como a perspectiva do Cuidado e a abordagem da psicologia social na saúde que o integra no Brasil, herdeiros da reforma sanitária e psiquiátrica que, desde os anos 1980, fundamentaram os princípios ético-políticos do Sistema Único de Saúde (SUS) e substituíram o antigo modelo asilar (Paiva, 2012b).

A vertente da psicologia social construcionista brasileira ampliou o modo de conceber a dimensão individual da vulnerabilidade proposta por Mann e Tarantola (1996), definindo-a como o plano da intersubjetividade (Ayres, Paiva, \& França, 2011, 2012). Isto é, substituiu a concepção de indivíduo biológico-comportamental a ser tratado em intervenções comportamentais pela de pessoas como sujeitos em ato, em diálogo, em contexto, em relação, reconstruídos constantemente na interação com os outros. Ressalta-se a pluralidade do sujeito, interpelado em sua vida cotidiana pela presença simultânea de discursos, frequentemente contraditórios, construídos social e historicamente e interiorizados ao longo da vida, processo mediado por outros significativos (pessoas ou instituições), encarregados de sua socialização. O processo de socialização (Berger \& Luckmann, 1987) constrói sentidos para a dinâmica da vida cotidiana, atualizados pelo sujeito a cada contexto intersubjetivo, a cada "cena" vivida de seu cotidiano (Paiva, 2006, 2007, 2008, 2009, 2012a).

A noção de cena, foco central da análise e da compreensão nesta vertente construcionista, privilegia a dimensão dramatúrgica, performática e interativa da intersubjetividade (inspirada em autores como Goffman, 1975, 1980). Desenvolvida nos estudos sobre promoção da saúde sexual e reprodutiva, essa noção compreende que cada "cenário" intersubjetivo mobiliza diferentes "scripts" - sistemas simbólicos que são traduzidos em códigos de conduta, compondo 
repertórios que se traduzem nas performances nas diferentes situações e interações (Gagnon \& Parker, 1995; Paiva, 2007, 2008, 2012a; Parker \& Aggleton, 1999; Simon \& Gagnon, 1984). Nessa vertente, a experiência concreta e singular da pessoa como "sujeito em cena" é a unidade de análise e o foco das ações em saúde.

Ainda no plano individual da vulnerabilidade, inextricavelmente implicado no plano programático e social (Ayres et al., 2011, 2012; Paiva, Ayres, \& Gruskin, 2010), destaca-se a concepção do paciente como usuário das ações de saúde, enquanto sujeito de direitos ou sujeito-cidadão - com direito à informação, direito à equidade no acesso aos serviços, direito à atenção integral à saúde (Paiva, 2006, 2009, 2012a). Perspectiva adotada na atuação no âmbito do SUS e, especialmente, no campo do HIV/ Aids, expressa a centralidade de valores como, por exemplo: o respeito ao direito à medicação e ao tratamento, ao sigilo sobre o diagnóstico de infecção pelo HIV e à autonomia da pessoa vivendo com HIV para tomar decisões sobre seu tratamento. Implicada na dimensão social e programática da vulnerabilidade, e portanto em ações derivadas dessa análise do processo saúde-doença, essa vertente construcionista valoriza autores que analisaram processos de estigmatização e discriminação nas interações sociais e na dinâmica da epidemia do HIV em particular (Parker \& Aggleton, 2001). Entende-se que as diferenças de gênero, cor/raça, orientação sexual, classe e idade são transformadas em desigualdades por práticas discursivas discriminatórias. Assim, desigualdades estruturais e institucionais que interferem na experiência cotidiana de viver com HIV, no acesso aos recursos disponíveis e na adoção de práticas de autocuidado, devem ser abordadas também no plano individual. No eixo programático, de especial interesse para este artigo, analisa-se a disponibilidade e a qualidade dos recursos a serem acessados pela população e pela pessoa, tais como programas e serviços organizados pelas diferentes esferas de governo. Nesse plano não se analisa ou se intervém apenas em investimentos materiais, mas também no compromisso político com a proteção de direitos que garantirão a redução da vulnerabilidade, nas ações de planejamento, avaliação e articu- lação intersetorial, bem como no fortalecimento da participação e dos mecanismos de controle social nas diversas etapas (Ayres et al., 2011, 2012; Paiva, 2009, 2012a).

Interdependentes, os três planos da vulnerabilidade devem ser abordados conjuntamente a cada situação enfocada. A análise sintética das três dimensões é possível, segundo essa proposta, ao abordar a "intersubjetividade em cena" (Ayres et al., 2011, 2012; Paiva, 2009, 2012a), "a pessoa no contexto e o contexto na pessoa" (Paiva, 2012a; Sato, 2005), expressões-síntese da esfera psicossocial. Nessa vertente construcionista, portanto, a concepção de atenção psicossocial, que raramente se define na literatura, adquire contornos específicos, integrada à noção de Cuidado desenvolvida por Ayres (2001, 2004).

A proposição do Cuidado busca a superação de um modelo de atenção excessivamente calcado na racionalidade científico-tecnológica. Enfatiza que as práticas em saúde envolvem também outro tipo de racionalidade - caracterizada como sabedoria prática e ligada à realização da vida, ou em outras palavras, ao que se almeja enquanto projeto de saúde e de felicidade, que se traduz no "exercício de escolha compartilhada de um modo de vida" (Ayres, 2004, p. 586). Propõe que o "êxito técnico", consolidado em "objetos" ou "produtos" do trabalho em saúde (por exemplo, o bom desfecho clínico do tratamento), não seja adotado como único critério de sucesso (Ayres, 2001). O horizonte normativo para a avaliação das práticas de saúde deverá incluir também a noção de "sucesso prático", que expressa processos de "antecipação, escolha e negociação de uma vida boa" (Ayres, 2004, p. 586) desenvolvidos nos encontros entre o profissional de saúde e o usuário. Nesse encontro entre sujeitos, destacam-se a dimensão comunicacional, relacional e dialógica assim como o caráter formativo dessa interação, no sentido da reconstrução de projetos de vida. Essa dimensão não pode ser reduzida "a uma apreensão cognitiva do tipo causa-efeito" que considere "os processos e resultados de qualquer componente técnico isolado do sentido que the imprime seu pertencimento ao arranjo tecnológico mais amplo onde está inserido" (Ayres, 2004, p. 589). Como proposta ético-filo- 
sófica, o Cuidado reafirma a ideia de que não se pode subtrair das pessoas a palavra última sobre suas necessidades.

No encontro profissional-usuário, que é o foco do Cuidado e da dimensão psicossocial sempre reconhecida no Cuidar, o usuário é definido como um especialista - especializado na sua própria vida e no manejo de seu cotidiano (Paiva, 2002, 2006, 2012a).

Nesta vertente psicossocial e construcionista, deve-se começar pela co-compreensão do sentido que as pessoas dão à sua experiência (Paiva, 2012a), em um exercício de codificação e decodificação, tal como definiu o educador Paulo Freire. Esse processo de "codificação", com propunha Freire para a alfabetização, começa com a descrição densa e a interpretação conjunta do sentido da experiência socialmente contextualizada da pessoa (Paiva, 2006, 2009, 2012a). A exploração de cenas estimula essa descrição almejando a ampliação da consciência da pessoa, tomada como sujeito dos discursos a que tem acesso (o da prevenção, o religioso, o de direitos), levantando seu repertório de práticas implicadas em cenários intersubjetivos, sócio-culturais e programáticos - ou seja, iluminando processos de estigmatização, de desigualdade e de exercício de direitos na experiência cotidiana, neste caso, de viver com Aids. ${ }^{4}$ Adotando-se a perspectiva da pessoa como cidadã, como sujeito de direitos, a atenção à saúde deixa de ser concebida como um produto pronto e um processo replicável em qualquer contexto de vida social, pessoal ou programático. Aposta-se na criatividade dos profissionais para a constante reconstrução de estratégias de Cuidado pautadas sobre a interação entre profissional e usuários (Ayres et al., 2011, 2012; Paiva, 2002, 2009, 2012a).

4 Essa proposição foi denominada em alguns textos como Abordagem da Emancipação Psicossocial (Paiva, 2002, 2009) em oposição às abordagens que concebem as pessoas como indivíduos consumidores de produtos e serviços (receitas, prescrições), buscando adequar suas condutas aos modelos de comportamentos pré-definidos, a serem ensinados, bem como à ideia de que lhes falta algo, que deveria ser tratado ou treinado.

\section{A Dimensão Psicossocial do Cuidado no Campo da Adesão}

Esse campo teórico - o quadro da vulnerabilidade, e suas referências ético- metodológicas para práticas de saúde desenvolvidas no Brasil - é congruente com as análises sobre adesão desenvolvidas na resposta brasileira à Aids e contrasta com a perspectiva da psicologia da saúde que aborda o comportamento de saúde para adequar / adaptar / corrigir / treinar o indivíduo-paciente, ou apenas "tratá-lo".

Define-se a adesão como um fenômeno complexo e dinâmico (Melchior, Nemes, Alencar, \& Buchalla, 2007; Nemes, 2009), que pode ser assim explicitado: as pessoas não são aderentes ou não aderentes. Elas estão, em um dado momento, seguindo seu tratamento com maior ou menor facilidade. No plano individual, interessa o modo particular como cada pessoa significa o seu tratamento, isto é, a forma como lida cotidianamente com a doença e com a necessidade de se submeter ao uso contínuo de medicamentos, considerando não apenas os aspectos biológicos, mas também a dimensão psicossocial do adoecimento - ganhando especial relevância, no caso da Aids, o sofrimento decorrente dos processos de estigmatização (Nemes, 2009). Como na abordagem psicossocial do Cuidado, as práticas de saúde são analisadas sob uma lógica compreensiva, significadas sempre à luz de uma totalidade interpretativa.

A situação viva de interesse é a tomada da medicação, que adquire significados distintos para cada sujeito e a cada contexto intersubjetivo. Em outras palavras, é diferente tomar os remédios em casa ou no trabalho. Cenários distintos contam com a participação de diferentes "atores" (que podem estar presentes fisicamente ou apenas no imaginário da pessoa): a mãe que vai chegar em casa, o colega que vai entrar no banheiro, ou o parceiro que pode encontrar os remédios na mochila. A cada "cena da tomada" da medicação, os discursos sobre a doença ou sobre o tratamento são atualizados - tais como o discurso místico que coloca que a melhora e a cura devem provir de uma instância divina; ou o discurso do médico que insiste na necessidade de tomar os remédios - e a conduta do sujeito 
expressará a saliência de um ou de outro discurso na espontaneidade mobilizada a cada cena.

Atenta-se, assim, às formas do sujeito conviver com o tratamento, observando-se a dinâmica das tomadas da medicação em meio às interações cotidianas que ocorrem nos diversos contextos intersubjetivos que a pessoa frequenta - dentre eles, o próprio serviço de saúde. A questão não é, então, saber se a pessoa "está tomando seus remédios direitinho", para usar uma expressão rotineiramente empregada por muitos profissionais de saúde ao abordarem o tema da adesão (Teixeira et al., 2000); mas sim de que forma ela está tomando e quais os significados que cada tomada da medicação adquire em sua vivência.
O usuário do serviço de saúde não está preocupado em seguir ou não a prescrição médica, mas em lidar com o tratamento da forma mais conveniente possível diante de seu contexto de vida, como a noção de sucesso prático permite pensar; nessa perspectiva pode-se admitir, sinceramente, a possibilidade de insucesso instrumental da intervenção, de permanecer cuidando de alguém que, apesar de interessar-se pelo cuidado, não está aderente - e eventualmente nunca venha a ficar. Não se trata de abandonar a finalidade técnica do trabalho, mas de assumir que esta não terá sentido enquanto não se configurar como legítimo sucesso prático (Nemes, 2009).

A proposta da ACCA é sintetizada na Figura 1, abaixo.

\section{Lógica}

Concepção de paciente

Compreensão da dimensão psicossocial da adesão

Foco da Intervenção

Principais objetivos das intervenções propostas

Principais resultados almejados

Dimensão normativa (que norteia a prática)
Compreensiva: procuram-se os significados que se fazem presentes, de forma contraditória e sincrônica, a cada cena ou contexto do cotidiano do sujeito

Como usuário, pessoa abordada com base na noção de integralidade, como sujeito plural, sujeito de diversos discursos a que tem acesso na socialização, especialmente como sujeito de direitos

A pessoa deve dar conta de discursos em disputa, negociados e atualizados pelo sujeito a cada cena da tomada dos remédios, cenas atravessadas por cenários sócio-culturais e programáticos, pela estigmatização, desigualdade de gênero e demais contextos de violação de direitos

Compreender a pessoa em cena, as cenas de tomada e os encontros programáticos para o Cuidado, estimulando a participação e o controle social como usuário

Decodificar com a pessoa os significados e contextos de suas práticas, em cenas e vivências; co-inventar novas possibilidades de interação em diferentes situações; definir "conveniências" e co-construir projetos de saúde e de felicidade; sugerir a ação na dimensão programática e social da vulnerabilidade ao adoecimento

Ampliação da consciência de profissionais e usuários a respeito de seus próprios repertórios e dos diferentes contextos de tomada dos remédios; melhora da convivência com o tratamento; mudanças no âmbito dos programas de saúde que apoiem a diminuição da vulnerabilidade social ao adoecimento

Além do êxito técnico, o sucesso prático (dimensão comunicacional, relacional, dialógica); êxito técnico que se configure como legítimo sucesso prático

Figura 1. Síntese da "Abordagem Construcionista do Cuidado em Adesão" (ACCA).

Este artigo insere-se em um projeto de pesquisa que avaliou uma intervenção desenhada no campo teórico descrito acima, conduzida no Centro de Referência e Treinamento de DST e Aids da Secretaria de Estado da Saúde de São Paulo (CRT-DST/AIDS-SP). O projeto de pesquisa como um todo enfocou a avaliação da efetividade da intervenção, bem como sua factibilidade e aceitabilidade, sob o ponto de vista das profissionais que a conduziram e dos usuários do serviço que participaram do estudo. ${ }^{5} \mathrm{O}$ objetivo do presente artigo é discutir, a partir da pers-

5 Outras análises estão atualmente em andamento, também conduzidas por pesquisadores que não participaram do processo de planejamento e realização da intervenção, enfocando a perspectiva dos usuários que participaram da intervenção e a análise da interação ocorrida nos encontros, gravados em meio magnético (esta discutida em Bellenzani \& Nemes, neste volume). 
pectiva de profissionais de saúde, se a ACCA é uma abordagem viável no contexto dos serviços públicos de saúde que atendem pessoas vivendo com HIV no Brasil e possível de ser conduzida por profissionais de diferentes disciplinas.

\section{Método}

Foram realizadas entrevistas em profundidade com as profissionais que conduziram a intervenção, em três etapas. As entrevistas foram realizadas por duas das autoras do presente estudo que não pertenciam ao corpo de funcionários do serviço sede da pesquisa, não participaram da condução empírica da pesquisa-intervenção e tampouco conheciam as profissionais ou os usuários que participaram da intervenção. Todas as entrevistas foram gravadas em meio magnético e transcritas.

$\mathrm{Na}$ primeira etapa, as entrevistas individuais usaram roteiro de 17 perguntas abertas que abordava: as dificuldades e facilidades que identificaram durante as atividades de capacitação e a intervenção; repercussões dessa experiência sobre sua prática no campo da Aids e, particularmente, no atendimento voltado para a melhoria da adesão; possibilidades e limites da proposta para auxiliar as pessoas vivendo com HIV a encontrarem formas de conviver melhor com seu tratamento; e desafios para uma futura incorporação da intervenção em outros serviços. A segunda etapa, uma entrevista em grupo, com o mesmo roteiro, possibilitou maior aprofundamento ao levantar diferenças e semelhanças na forma como cada uma vivenciou o processo. $\mathrm{Na}$ terceira etapa, nova rodada de entrevistas individuais detalhou a descrição dos encontros com alguns participantes e exemplos de situações vivenciadas nesses casos. $\mathrm{O}$ roteiro propunha que escolhessem dois casos de pessoas atendidas no processo de intervenção da pesquisa, um que considerassem "bem-sucedido" e o outro "malsucedido". Em seguida, solicitou-se que relatassem brevemente sua experiência na condução dos encontros com os partcipantes selecionados e expusessem os critérios que adotaram para atribuir a caracterização de "sucesso" ou "fracasso" a esses casos. Duas das profissionais optaram por acrescentar um terceiro caso, descrito por elas como "intermediário" em relação ao sucesso, totalizando assim oito casos eleitos.

$\mathrm{Na}$ análise, o conteúdo do material em áudio e transcrito das entrevistas foi analisado com base nos temas previamente estabelecidos: atividades de capacitação, sessões de supervisão, condução dos encontros, repercussões da abordagem para a prática profissional, benefícios percebidos para os participantes, e implantação futura da intervenção nos serviços.

Nessa análise de conteúdo, procuraram-se semelhanças e diferenças nas falas das profissionais, e entre as etapas. As falas citadas no texto foram identificadas com nomes fictícios - Mari$n a$ (assistente social), Joana (psicóloga que atua na área de assistência) e Renata (psicóloga que atua nas áreas de prevenção e gestão) - seguidos de siglas indicando se os trechos foram retirados das entrevistas individuais (E. I.) ou da entrevista coletiva (E. C.). Os trechos foram selecionados apenas para ilustrar a análise, de modo que não há igual número de citações para as falas de cada uma das três profissionais.

Produzimos, então, um debate em torno dos relatos apresentados, resgatando experiências anteriores pautadas no mesmo referencial teórico que embasou a intervenção. Não abordamos nessa discussão a dimensão da efetividade da intervenção, isto é, os resultados do ensaio clínico que a avaliou (ver abaixo).

O presente estudo, assim como o projeto da pesquisa original, encontra-se em conformidade com as diretrizes e normas de pesquisas envolvendo seres humanos (Resolução 196/1996 do Conselho Nacional de Saúde) e ambos foram aprovados pelo Comitê de Ética em Pesquisa do Centro de Referência e Treinamento em DST/ Aids de São Paulo (CRT-DST/AIDS-SP). As profissionais e os usuários participantes foram previamente informados dos objetivos da investigação, concordaram em participar, leram e assinaram Termo de Consentimento Livre e Esclarecido e suas identidades foram preservadas.

\section{Síntese do Processo de Intervenção Realizada}

As experiências de ações de promoção da saúde nessa abordagem têm sido acumuladas principalmente no campo da saúde sexual e re- 
produtiva. A proposta da ACCA adaptou os mesmos referenciais para uma intervenção individual para melhoria da adesão.

A pesquisa foi motivada pela necessidade, percebida pelo Programa Estadual de DST e Aids de São Paulo e apontada em estudos anteriores conduzidos pela Equipe Qualiaids ${ }^{6}$ de se ampliar o conhecimento acerca das atividades de adesão que fazem parte da rotina dos serviços de aids do estado de São Paulo. Foi realizada pela parceria entre os dois grupos. A primeira fase caracterizou as atividades voltadas para melhoria da adesão nos serviços do SUS (Caraciolo, 2010; Caraciolo et al., 2009). A segunda fase, que discutiremos, construiu e testou o modelo de intervenção potencialmente efetivo para melhorar a forma de as pessoas vivendo com HIV conviverem com seu tratamento (Nemes, Equipe Qualiaids, \& CRT-DST/AIDS-SP, 2009).

A construção do modelo ACCA foi baseada na experiência acadêmica e prática dos integrantes da equipe de pesquisa e na revisão da literatura nacional e internacional sobre intervenções em adesão; e em uma oficina de trabalho com profissionais com experiência em condução de atividades de adesão nos serviços do estado de São Paulo e com profissionais e acadêmicos com reconhecida experiência no campo da Aids que adotam o quadro da vulnerabilidade e dos direitos humanos.

O desenho de um protocolo de intervenção individual foi, então, testado em ensaio clínico pragmático (Basso, 2010; Basso, Santa-Helena, Caraciolo, Paiva, \& Nemes, 2012) conduzido em 2008 no CRT-DST/AIDS-SP. Participaram do estudo usuários com mais de 18 anos, em tratamento antirretroviral com o mesmo esquema há pelo menos seis meses e com carga viral detectável (>50cópias $/ \mathrm{ml}$ ) nos 120 dias prévios ao início do recrutamento, distribuídos aleatoriamente em dois grupos, de intervenção e controle. Ambos receberam o cuidado usual do serviço. Os participantes do grupo-intervenção foram convidados a participar de quatro encontros individuais com um profissional de saúde

6 Sobre a Equipe Qualiaids acessar www.qualiaids. blogspot.com (sintetizados na Tabela 1). Compararam-se as medidas de adesão (obtidas por meio de sistema de monitoramento eletrônico das tomadas) e de carga viral dos dois grupos, durante seis meses de seguimento.

Ao final dos quatro encontros, pretendia-se que profissional e usuário planejassem a sustentação do autocuidado dali em diante, reconhecendo os limites e as possibilidades em jogo e identificando formas de apoio ao usuário disponíveis no serviço.

Três profissionais do serviço foram selecionadas para conduzir a intervenção, entre dez candidatos que participaram das atividades de capacitação. A seleção foi feita com base nos seguintes critérios: apreensão, aceitação e desempenho da abordagem proposta; habilidade para estabelecer uma comunicação fundada no diálogo, na escuta ativa e no estímulo à participação do usuário; capacidade de atuar como multiplicador do modelo de intervenção testado, caso se mostrasse efetivo; disponibilidade para participar das reuniões do projeto; e compromisso com assiduidade e pontualidade na realização das atividades.

O processo de capacitação fundamentou-se na metodologia problematizadora desenvolvida por Paulo Freire (1987), e utilizou vivências e discussões nas quais as profissionais foram convocadas a dialogar com seus próprios conceitos, valores e práticas, revisitando-os à luz do referencial da ACCA. Por exemplo, a experiência em que as profissionais simularam a tomada de medicação por 48 horas, como fazem os usuários, utilizando placebos; e role-playings em que simulavam a condução da intervenção junto a atores profissionais ou colegas que atuavam no papel de um usuário. Ao final da capacitação, as profissionais realizaram um piloto da intervenção junto a voluntários que não participaram da fase de intervenção da pesquisa.

A intervenção almejou aprofundar o diálogo em torno das dificuldades da pessoa para tomar a medicação, partindo dos significados que o tratamento adquire em meio ao seu contexto geral de vida e da identificação de cenas em sua narrativa que os expressassem concretamente, ou da estimulação à sua produção pelo usuário, explorando cenas vividas ou imaginadas por 
ele, ou seja, exercitando a imaginação ativa $^{7}$ e, eventualmente, a sua dramatização. A atividade, abordada na capacitação, pode ser desenvolvida com as pessoas sentadas normalmente em cadeiras do ambulatório, adensando a conversa na forma do relato de casos, com falas vivas e a imaginação ativada. Como propôs Paiva (2005, 2012a), a tarefa do profissional é levar o usuário a descrever densamente as situações de seu dia a dia, identificar os contextos em que ocorrem e os personagens que se fazem presentes na situação (familiares, amigos, parceiros, profissionais de saúde, colegas de trabalho, patrão, outras pessoas com HIV etc.), trazendo à tona suas diferentes falas e os sentidos de cada fala ou ação. A exploração da cena sob diversas perspectivas estimula a pessoa a reinventar os modos de conduzi-la. $\mathrm{O}$ profissional age como se fosse um diretor, isto é: pede esclarecimentos sobre os cenários - o palco (lugar) onde se desenvolve a ação e seu contexto social - e os papéis representados; e solicita frequentemente a repetição de partes da cena, a troca de papéis, a ampliação do palco onde a cena se realiza para um cenário social, cultural, econômico e institucional mais amplo etc. Esgotadas as possibilidades de exploração da cena, profissional e usuário passam a conversar sobre os aspectos que emergiram do exercício, tais como: a recuperação e compreensão de como as situações relatadas aconteceram; qual o seu contexto mais amplo; que novos sentidos podem ser atribuídos a essas situações; e que novos caminhos e soluções podem ser pensados para se lidar com as dificuldades percebidas.

Os encontros foram registrados em instrumentos de dois tipos: um registro preenchido ao final de cada encontro, cujo conteúdo era acordado entre profissional e usuário, contribuindo para o processo de pactuação em torno das temáticas trabalhadas e caracterizando-se, assim, como um componente da intervenção; e um instrumento individual em que as profissionais relatavam brevemente o encontro ocorrido, registrando suas impressões e as dificuldades encontradas para conduzir a sessão.

Tabela 1

Objetivos e Estrutura da Intervenção da ACCA*

\begin{tabular}{llll}
\hline & Sessão 1 & Sessões 2 e 3 & Sessão 4 \\
\hline Objetivos & Contrato; & $\begin{array}{l}\text { Aumentar } \\
\text { o conhecimento } \\
\text { sobre o tratamento; }\end{array}$ & $\begin{array}{l}\text { Aprofundar a compreensão de } \\
\text { mudanças possíveis e desejadas } \\
\text { no contexto e na própria conduta } \\
\text { visando o autocuidado e a melhoria } \\
\text { da qualidade do cuidado e da } \\
\text { comunicação usuário-profissional; }\end{array}$ \\
$\begin{array}{llll}\text { Identificar situações e } \\
\text { contextos da vida cotidiana } \\
\text { que constituem obstáculos } \\
\text { para o tratamento; }\end{array}$ & $\begin{array}{l}\text { Compreender } \\
\text { e decodificar cenas } \\
\text { da vida real; }\end{array}$ & $\begin{array}{l}\text { Identificar recursos para busca } \\
\text { e sustentação dos caminhos } \\
\text { escolhidos para o enfrentamento } \\
\text { das dificuldades com o tratamento } \\
\text { antirretroviral; }\end{array}$
\end{tabular}

Definir temas e questões prioritárias a serem trabalhadas nos encontros seguintes; programático maior; Ampliar as cenas para um contexto social e Finalizar o processo.

Finalizar o processo.

\author{
Aprofundar a compreensão de \\ visando o autocuidado e a melhoria \\ da qualidade do cuidado e da \\ municação usuario-profissional;

\begin{abstract}
Identificar recursos para busca e sustentação dos caminhos
\end{abstract} (n) 
Resolver dúvidas técnicas sobre o tratamento.
Estimular a imaginação

ativa e criativa sobre

a vida cotidiana;

Estimular novos repertórios

para o enfrentamento dos

obstáculos identificados

para o tratamento.

\begin{tabular}{|c|c|c|c|}
\hline \multirow[t]{4}{*}{ Temas } & $\begin{array}{l}\text { Reconhecimento mútuo do } \\
\text { usuário como expert da vida } \\
\text { cotidiana e do profissional/ } \\
\text { pesquisador como expert } \\
\text { técnico; }\end{array}$ & $\begin{array}{l}\text { Questões sobre o } \\
\text { tratamento; }\end{array}$ & Questões sobre o tratamento; \\
\hline & $\begin{array}{l}\text { Revisão do contexto social } \\
\text { e intersubjetivo do usuário; }\end{array}$ & $\begin{array}{l}\text { Episódios reais em que o } \\
\text { tratamento não é seguido; }\end{array}$ & $\begin{array}{l}\text { Revisão de caminhos, soluções e } \\
\text { repertórios; }\end{array}$ \\
\hline & Questões sobre o tratamento. & $\begin{array}{l}\text { Caminhos para o } \\
\text { enfrentamento de obstáculos } \\
\text { e soluções "em cena". }\end{array}$ & $\begin{array}{l}\text { Conversa sobre como enfrentar } \\
\text { futuros obstáculos e dificuldades e } \\
\text { manter as mudanças; }\end{array}$ \\
\hline & & & $\begin{array}{l}\text { Esclarecimentos e orientações } \\
\text { finais da pesquisa. }\end{array}$ \\
\hline \multirow[t]{8}{*}{ Metodologia } & $\begin{array}{l}\text { Discussão dos } \\
\text { procedimentos, objetivos } \\
\text { e contrato; }\end{array}$ & $\begin{array}{l}\text { Revisão do contrato e das } \\
\text { questões levantadas; }\end{array}$ & $\begin{array}{l}\text { Revisão do contrato e das questões } \\
\text { levantadas; }\end{array}$ \\
\hline & $\begin{array}{l}\text { Livre conversação e escuta } \\
\text { atenta sobre a vida da } \\
\text { pessoa; }\end{array}$ & $\begin{array}{l}\text { Identificação de episódios } \\
\text { típicos } \\
\text { de não adesão; }\end{array}$ & $\begin{array}{l}\text { Identificação e exploração de cenas } \\
\text { de episódios reais; }\end{array}$ \\
\hline & $\begin{array}{l}\text { Foco em questões do } \\
\text { tratamento e em situações } \\
\text { e episódios em que há } \\
\text { dificuldade para seguir } \\
\text { o tratamento; }\end{array}$ & $\begin{array}{l}\text { O participante escolhe suas } \\
\text { prioridades de uma lista de } \\
\text { problemas; }\end{array}$ & $\begin{array}{l}\text { Decodificação e reinvenção de } \\
\text { cenas por meio da imaginação ativa } \\
\text { e de role-playing; }\end{array}$ \\
\hline & $\begin{array}{l}\text { Uso de recursos } \\
\text { informativos (folders, } \\
\text { guias, kits de adesão); }\end{array}$ & $\begin{array}{l}\text { Identificação e exploração } \\
\text { de cenas de episódios reais; }\end{array}$ & $\begin{array}{l}\text { Informação sobre recursos sociais } \\
\text { e programáticos, bem como sobre } \\
\text { direitos constitucionais; }\end{array}$ \\
\hline & $\begin{array}{l}\text { Registro das situações e } \\
\text { episódios que parecem } \\
\text { importantes para o } \\
\text { enfrentamento em folhas } \\
\text { de registro. }\end{array}$ & $\begin{array}{l}\text { Decodificação e reinvenção } \\
\text { de cenas por meio da } \\
\text { imaginação ativa e de role- } \\
\text { playing; }\end{array}$ & $\begin{array}{l}\text { Registro de decisões e planos para } \\
\text { o futuro em folhas de registro. }\end{array}$ \\
\hline & & $\begin{array}{l}\text { Conversa sobre obstáculos } \\
\text { que estão além da } \\
\text { ação individual e são } \\
\text { compartilhados por outras } \\
\text { pessoas vivendo com HIV; }\end{array}$ & \\
\hline & & $\begin{array}{l}\text { Discussão de recursos } \\
\text { individuais e programáticos; }\end{array}$ & \\
\hline & & $\begin{array}{l}\text { Profissional e usuário } \\
\text { registram e organizam } \\
\text { hierarquicamente cenas } \\
\text { e situações em folhas de } \\
\text { registro. }\end{array}$ & \\
\hline
\end{tabular}

Nota. * Tabela extraída e traduzida de Basso et al., 2012. 
Diante do ineditismo da proposta, bem como da necessidade de se obter um grau de homogeneidade na execução da intervenção que sustentasse um ensaio clínico pragmático e a reflexão crítica sobre o processo, o protocolo incluiu sessões coletivas de supervisão para as profissionais. As supervisões foram conduzidas por profissionais da área médica que compunham a equipe de pesquisa e por uma psicóloga experiente na metodologia das cenas no campo da Aids.

\section{Resultados e Discussão}

De modo geral, as profissionais valorizaram a oportunidade de participar da pesquisa e indicaram que a experiência trouxe-lhes repercussões marcantes para sua atuação profissional para além da temática da adesão ao tratamento antirretroviral. Segundo os depoimentos das três entrevistadas, a proposta da ACCA possui um caráter inovador e tem o potencial de levar os profissionais que atuam na área da assistência a reverem e transformarem suas práticas de atendimento, no sentido de priorização da perspectiva do usuário e de aprofundamento da conversa, abordando seu contexto de vida. Vale ressaltar que as três profissionais tinham grande experiência na área, todas com mais de 15 anos de trabalho no serviço.

\section{Capacitação e Supervisão}

Desde a capacitação, a transformação da prática foi destacada:

eu fiquei meio insegura, achei até que não fosse dar conta. . . . Porque .. . há 15 anos você atende de uma forma, então foi como se eu tivesse que desconstruir tudo que eu já aprendi e tivesse que construir tudo de novo. (Marina, E. I.)

As entrevistadas apontaram que este processo de desconstrução da prática - especialmente a revisão de um modelo de atuação pré-determinado, independentemente da singularidade do usuário, que não valoriza o diálogo - constitui um especial desafio a ser enfrentado na implantação do modelo em outros serviços. No caso específico da instituição em que a pesquisa foi realiza- da, consideraram que a apropriação das noções propostas pela ACCA foi facilitada porque eram princípios de trabalho já disseminados no CRT-DST/AIDS-SP, realidade não encontrada na maioria dos serviços.

Nesse sentido, as entrevistadas ressaltaram que a promoção de uma reflexão crítica dos profissionais sobre as práticas habituais consistiria etapa fundamental das atividades de capacitação e que um maior investimento nessa etapa inicial seria necessário para mobilizar os profissionais a entrarem em contato com novas formas possíveis de atuação: "eu acho que a gente não vai mudar os profissionais, mas que eles percebam os limites daquele atendimento" (Renata, E. C.).

Destacaram, também, a importância da supervisão para complementar o aprendizado da capacitação. Consideraram importante o fato de médicas serem supervisoras. A interlocução entre diferentes saberes (medicina, psicologia e serviço social) mostrou-se fundamental para que pudessem aprimorar o diálogo com os usuários em torno das questões relacionadas ao uso dos medicamentos - incluindo aspectos do tratamento que geralmente são de domínio exclusivo da área médica.

Ao mesmo tempo, sendo a intervenção pautada pela ideia de priorização da perspectiva do usuário, puderam valorizar igualmente a abordagem de questões que não estavam diretamente relacionadas à tomada dos remédios. Um dos tópicos discutidos em supervisão foi justamente a dificuldade percebida pelas profissionais em diversos encontros para focar a conversa no tema da adesão. Reconheceu-se, assim, que há situações em que é preciso deixar de lado a questão dos medicamentos para priorizar a demanda espontânea do usuário, para que a temática da adesão possa ser retomada posteriormente de forma mais integrada ao seu contexto de vida, situação exemplificada no depoimento de Joana:

Esse caso é de uma moça . . . muito dependente da filha . . mora . . . no mesmo quintal ... A filha casada tinha uma bebê de um ano ... ela [a participante] veio muito mal .. porque essa filha estaria mudando para o nordeste; e por mais que eu quisesse conduzir ... para o lado da nossa proposta, ela 
trazia essas questões. Aí eu . . deixei fluir . . . eu me recordo que ela falou para mim assim: "Olha ... Eu não estou a fim de falar, eu quero mais é sair daqui. Eu estou me sentindo muito mal". Eu falei: "Tudo bem, é um direito seu". Eu respeitei . . . ai ela se abriu. . . ela me contou que bateu na bebê ... pegou o sapato e bateu na cabeça. Ela estava sentindo muita culpa . . estava com um processo de uma depressão. ... ela tinha muita raiva do ex-marido dela, que passou o HIV .... E aí foi muito legal porque ... ela trouxe todas as questões . . Tanto que no outro encontro a gente conseguiu resgatar tudo o que realmente tinha a ver com toda a história dela . . E [o] medicamento . . ela associava muito à questão afetiva, se está mal com a filha não toma. (Joana, E. I.)

$\mathrm{O}$ reconhecimento dessa necessidade indica que as profissionais se apropriaram da proposta de uma postura dialógica, sensível às necessidades do usuário a cada momento.

Com o auxílio das sessões de supervisão, as profissionais foram adquirindo maior autonomia na condução dos encontros, ao perceberem que não era preciso seguir com rigidez o roteiro de intervenção proposto na capacitação, respeitando a singularidade de cada interação:

cada situação é uma situação nova, então a dificuldade que eu tive no começo foi de querer aplicar o que a gente aprendeu, da forma que a gente aprendeu . . . mas tem momentos que não precisa ser bem daquela forma . . . e isso eu aprendi na supervisão. (Marina, E. I.)

Sem desconsiderar que o contexto de pesquisa exigia uma padronização mínima do formato da intervenção, as profissionais indicaram aspectos do protocolo a serem flexibilizados em uma implantação futura: o número total de encontros e o tempo de duração de cada encontro, a serem reduzidos ou estendidos de acordo com a relação estabelecida com cada usuário. Ao mesmo tempo, consideraram interessante o fato de haver um período de intervenção previamente definido, delimitando "um começo, um meio e um fim" (Renata, E. I.).

Destacaram, ainda, o papel da supervisão na ampliação de seu entendimento sobre as formas possíveis de exploração de cenas do cotidiano junto aos usuários, que as ajudou a compreenderem que a estratégia não se restringia ao uso do recurso de dramatização:

no inicio. . tinha uma expectativa grande . . . da minha parte de trabalhar cena, mas a cena dramatizada. . . na supervisão. . . a gente. . foi identificando. . que. . o fato da pessoa contar. . o que se passou na vida dela ...já é uma vivência de cena. (Marina, E. I.)

Vale ressaltar que, na proposta da ACCA, espera-se que a metodologia das cenas não seja introduzida artificialmente, mas apenas na medida em que ajude o profissional a aproximar-se da vivência do usuário. A ideia é integrar outros instrumentos e práticas originárias da formação disciplinar a essa abordagem.

\section{Condução dos Encontros}

$\mathrm{O}$ recurso das cenas, segundo as entrevistas, enriqueceu a conversa sobre as formas de convivência com o tratamento e contribuiu para que os usuários introduzissem novos elementos em seus relatos sobre as dificuldades em seu dia a dia, e reformulassem suas questões iniciais. Permitiu que o diálogo fosse além das soluções prontas e discursos consolidados para encontros sobre adesão. É expressivo o relato do atendimento de um participante que, desde o primeiro encontro, dizia que tinha dificuldade em tomar o remédio corretamente em função da ausência de uma rotina de horários em seu cotidiano. A profissional tentou levantar a possibilidade de um horário em que ele estivesse acordado todos os dias e pudesse fixar a tomada de seus remédios. No terceiro encontro, propôs a exploração dramática de uma cena de tomada no horário em que ele costumava sair de casa para trabalhar:

"Tá, então 23h00, por que você não toma o seu remédio?" / "Ah, porque eu acordo atrasado e esqueço de pegar o remédio". Eu falo: ". . . faz a cena de você acordando atrasado". Dai ele acorda atrasado . . . Pega a pasta, pega o celular, dai vem o questionamento: "Por que você lembra de pegar o celular, mas você não lembra de pegar o seu remédio?" Dai ele pára para 
refletir . . . com os meus comentários: " $O$ que pode fazer você lembrar do remédio?" . . . ele não consegue pensar, dai eu sugiro: “. . . Então põe um recado na porta".

Ele escreveu um recado ... ele surtou nesse momento, começou a chorar, travado, ele não conseguia se mover. . . Eu tive que levantar, abraçá-lo, perguntar se ele estava com medo: "Vamos conversar sobre esse seu sentimento". Ele não queria falar. . . depois . . . de uns 15 minutos assim nessa situação . . ele . . acalma . . Daí ele me fala que ele não sabe o que ele sente nesse momento, ele não consegue identificar qual é o sentimento, se é . . de tristeza, se é de medo, se é de raiva porque ele está com HIV . . . a gente juntos . . conseguiu perceber que a questão dele não tomar o remédio não é . . problema do atraso ... Ele tem que descobrir qual é essa questão . . que ele identificou como importante . . e ele vai trabalhar na terapia. (Marina, E. C.)

Para a profissional, nesse caso a vivência de cena propiciou "um outro entendimento da situação dele ... foi bem importante porque fez ele perceber que a questão . . . não estava fora, estava nele mesmo" (Marina, E. I.). Ou seja, a partir do exercício, identificaram novos aspectos relacionados à sua dificuldade e, embora não tenham chegado a nomear nesse momento, a necessidade de dar continuidade a um atendimento onde pudesse seguir aprofundando essas questões ficou clara.

Segundo as entrevistadas, alguns aspectos se mostraram relevantes para a decisão sobre o uso ou não do recurso das cenas: a disponibilidade do participante, a cada encontro, para abordar questões de seu cotidiano e para refletir sobre seus modos de conviver com o tratamento; a constituição de um vínculo entre profissional e usuário que proporcionasse abertura da parte de ambos para avançarem no diálogo; e a possibilidade de esse recurso fazer sentido para o usuário, de acordo com seu repertório, sua trajetória e seu momento de vida. Observaram, por exemplo, que muitas pessoas faziam uso de cenas de forma espontânea na conversa como uma "contação de casos", trazendo exemplos de situações concretas. Nesses atendimentos, os recursos dramáticos mostraram-se interessantes para incrementar a conversa e para tornar a decodificação de cenas mais explícita para o usuário.

Porém, houve casos em que a introdução dessa estratégia não foi possível. Em um dos casos atendidos, a profissional observou que o estabelecimento de empatia foi prejudicado pela postura irônica e provocativa da participante desde o primeiro encontro:

tudo que você fazia . . ela . . detonava e destruía. . . . foi dificil lidar com ela . . . Era uma pessoa extremamente arredia . . . tinha acho que prazer mesmo de provocar. (Joana, E. I.)

Ainda, características do contexto sociocultural, ou situações específicas como a depressão ou o recente conhecimento do diagnóstico, foram também percebidas pelas profissionais como obstáculos para o estabelecimento de vínculo e, portanto, para o desenvolvimento do processo interativo.

A dificuldade em transpor diferenças culturais foi exemplificada pelo caso de um participante de etnia oriental. A profissional atribuiu a impossibilidade de criar vínculo com ele à comunicação difícil:

você percebia que tinha um código ali na hora de conversar . . . não sei se fosse alguém que entende mais o que é ser japonês ... [é] uma forma muito específica de se comunicar . . . você não sabe . . na linguagem não verbal também, o que é que a pessoa está expressando . . Houve uma distância entre a gente que eu acho que não pôde ser superada. . . Os quatro encontros não foram suficientes para conseguir uma proximidade no nível que a gente conseguiu com os outros pacientes. . . da cumplicidade do processo, de fazer um vínculo mesmo. (Renata, E. I.)

Em outra tentativa malsucedida na exploração de cenas, segundo a profissional, o participante "não via sentido no que estava fazendo" (Marina, E. I.). Nesse caso, a profissional observou, também, que ele parecia estar deprimido e, dentre outras dificuldades que relatava em relação ao seu contexto de vida, mostrava-se 
bastante mobilizado pela recente descoberta do diagnóstico do HIV. A profissional atribuiu o "fracasso" desse atendimento à "pouca disponibilidade" do participante "para qualquer tipo de sucesso" (Marina, E. I.).

Já o maior grau de escolaridade foi citado como um possível elemento facilitador do entendimento do recurso das cenas no caso de uma pessoa que tinha "uma escolaridade legal" (Renata, E. I.) e que "desde o primeiro momento ... aderiu à proposta" (Renata, E. I.):

Para ela [a participante] fez sentido a coisa das cenas. . . deu para fazer umas cenas legais. . Ela levantou da cadeira, olhou para ela no atendimento. . . Ela se emocionou com isso, depois ela mesma refletiu sobre isso, elaborou isso. . . depois traz isso de novo como sendo de muita importância.

(Renata, E. I.)

A ruptura com pré-conceitos e a maior valorização da singularidade dos usuários, por outro lado, foram ressaltadas pelas entrevistadas como contribuições fundamentais da ACCA para a dimensão psicossocial do Cuidado, destacadas com ênfase no relato da profissional que atua na área da assistência social. Ela se refere à sua experiência na pesquisa da seguinte forma: " $\mathrm{Mu}$ dou . . . a minha visão de atenção ao usuário. ... Porque eu sempre mobilizei os meus repertórios para serem utilizados de outra forma" (Marina, E. I.). A profissional citou como exemplo o caso de uma travesti, que ela própria já havia acompanhado no serviço:

eu atendi ela durante . . . cinco anos . . . deixei de atender e eu vim a atender novamente na pesquisa. . . . no primeiro e no segundo encontro ela já falou para mim: "Nossa, Marina! Até que enfim essa conversa, não é?" Eu falei: "Realmente . . e eu te atendi durante tantos anos e demorou tanto para a gente ter uma conversa igual a gente teve hoje". (Marina, E. I.)

O salto na abordagem deste caso decorreu da recuperação da história de vida e do aprofundamento na compreensão sobre as dificuldades para conviver com o tratamento diariamente. A entrevistada comparou essa postura com a perspectiva adotada habitualmente pelos profissio- nais no "diálogo" com os usuários, que exemplificou:

"Você não está tomando remédio? . . você tem que tomar na hora, viu? . . E por que você não toma?" / "Ah! Eu esqueço". " . . . você tem que providenciar um relógio". I "Tá bom, eu vou providenciar". ". . . Olha, você não pode usar drogas. Tem que fazer um tratamento para parar de usar drogas. . .. Então você... procura tal lugar?" / "Ah! Tá bom, procuro". . . É diferente do que você trabalhar na percepção do usuário: "Não, na verdade eu não tomo o remédio direito, não é só porque eu uso droga, é por várias outras questões". E você trabalhar as questões e contemplar essas questões de uma outra forma. Porque é fácil para o profissional, você identifica a dificuldade e encaminha: "Ah! Então, vai para a psicologia ... vai para o psiquiatra"... Agora você e o usuário, você contemplar o que ele está te trazendo, na sua totalidade, é fundamental. Eu estou achando esse processo fantástico. (Marina, E. I.)

\section{Repercussões para a Prática Profissional}

De acordo com a assistente social, a prática do serviço social dificilmente prioriza a perspectiva do usuário: "A gente . . quando atende o usuário, já está meio armado aonde. . . vai encaminhar . . como que se já tivéssemos dado conta daquela situação que ele está trazendo" (Marina, E. C.). A entrevistada ressaltou que as soluções buscadas na interação baseiam-se frequentemente em pré-concepções a respeito do perfil de cada população, pautando-se em "questões de grupo" e em "dados epidemiológicos", que costumam levar a raciocínios como, por exemplo: "como . . . os grupos de travesti lidam com essa situação" (Marina, E. C.). Isto se dá, segundo a profissional, em detrimento da singularidade da pessoa que de fato está sendo atendida: "a gente não pode se prender só a esses indicadores ... às vezes, aquele travesti tem uma característica completamente diferente" (Marina, E. C.). 
A necessidade de superar discursos consolidados em relação à adesão também foi ressaltada. Em outro caso, a assistente social notou que a pessoa contava com bastante apoio familiar para seu tratamento e que essa informação poderia ter lhe parecido suficiente em um primeiro momento; mas que, nesse caso, foi fundamental aprofundar a compreensão da forma como se dava, de fato, essa relação:

A gente acha bom a familia ajudar ... mas no caso dela, eles ajudavam muito ... Ficavam lembrando ela de tomar o remédio dela toda hora . . . Ela queria continuar nesse papel. ... Na verdade, ela estava acomodada nessa história. (Marina, E. I.)

A entrevistada observou que, embora os aspectos relacionados tanto ao tratamento quanto ao contexto de vida dos usuários sejam usualmente abordados nos atendimentos, dificilmente ambos são trabalhados de forma integrada, com base em uma cena e situação:

normalmente a gente . . discute o HIV, mas não dentro do cotidiano do usuário. . . . a gente até traz esse contexto de vida . . . essas questões à tona, mas . . . A gente não discute... É como se uma coisa não fizesse parte da outra. (Marina, E. I.)

A noção de conveniência ${ }^{7}$ com o tratamento foi uma ferramenta valorizada pelas entrevistadas na operacionalização da abordagem da ACCA, considerada como formulação simples e capaz de nortear as ações do profissional. Uma das entrevistadas, que atua na área da gestão, relatou que a noção de conveniência e o recurso das cenas foram incorporados em sua prática de capacitação de outros profissionais:

Não basta você ouvir . . você identificar as necessidades [das pessoas atendidas] e você vai fazer o quê com isso? Então agora eu tenho uma ferramenta . . a técnica de trazer para uma coisa concreta, é possivel de todo

\footnotetext{
A noção de conveniência diz respeito à ideia de priorizar, no encontro entre profissional e paciente, aquilo que convém ao paciente, diante de seu contexto de vida e de seu cotidiano. Está relacionada à noção de "projetos de felicidade", definida por Ayres (2004).
}

mundo entender e as pessoas [profissionais de saúde] ficam mais aliviadas porque elas sabem o que elas têm que fazer, como é que isso se dá na relação ... amadureceu o meu discurso ... porque chegava nessa hora... Eu sabia o que eu queria dizer, mas não tinha instrumentos para dar para as pessoas de uma forma rápida, objetiva, onde ela tem que chegar ... qual é a meta desse trabalho. Antes era uma coisa vaga . . Agora não, você fala assim . . " "nós vamos trabalhar: o que é conveniência? Qual é o foco? ... E ai você faz o quê com isso? Tem 15, 20 minutos, como é que você faz isso?" (Renata, E. C.)

Outro ponto que indicou a incorporação do referencial da ACCA pelas profissionais está relacionado à mudança na concepção sobre o sucesso ou o fracasso dos atendimentos, implicada na noção de Cuidado. Notamos que as avaliações a respeito dos casos atendidos não se restringiram à dimensão do êxito técnico, levando em consideração o sucesso do ponto de vista do próprio usuário. É relevante nesse sentido o fato de que, nas entrevistas, as profissionais optaram espontaneamente por eleger casos intermediários, isto é, por incluir exemplos bem-sucedidos do ponto de vista da dimensão comunicacional e em relação à perspectiva do usuário, mas que não necessariamente levaram a um aumento da adesão.

A incorporação da noção de sucesso prático pelas profissionais permitiu a aceitação da decisão dos usuários que, em casos extremos, opunha-se explicitamente ao êxito técnico, como no caso de uma pessoa que tomava medicação injetável (T20), cuja auto-aplicação diária representava uma grande dificuldade, deixando-lhe marcas e pontos doloridos no corpo. Ao longo do processo, ele chegou a tirar dúvidas com a enfermeira e a frequentar um grupo para pessoas que usavam o T20, mas a dificuldade permaneceu. Decidiu, então, que não usaria na frequência prescrita pelo médico. A profissional alertou-o dos riscos de tomar a medicação irregularmente, concluindo que ao final "nem ele parou, nem ele tomou corretamente, nem ele viu uma chance de superar a dificuldade. . um fracasso técnico 
completo" (Renata, E. I.). Entendeu, entretanto, que houve sucesso prático nesse caso:

para aquele ser humano, nunca será conveniente tomar o T20, ele tomou a decisão. Ele não encontrou um acordo de quem ele é e como ele vive, o que ele espera da vida, $e$ o que esse remédio exige dele. . . . Do ponto de vista tradicional, nós fracassamos, porque ele disse que ele não vai tomar o remédio. Do ponto de vista existencial para esse sujeito . . . ele é capaz de me dizer: "Isso que vocês estão querendo me oferecer, não é possivel conciliar com quem eu sou. Eu estou tranquilo, se for morrer o preço, eu vou morrer, mas eu não consigo. Neste momento é inegociável". Com esse conceito, nós não fracassamos. .. . Porque nós munimos o cara de todos os instrumentos possíveis, informação, alternativas, para que ele pudesse chegar a essa conclusão de forma menos conflituosa possivel, consigo mesmo. É claro que uma parte dele talvez tenha medo de morrer, mas a gente permite uma fala que jamais a gente permitiria. . . De [ele] dizer para a gente: "Eu não vou fazer isso. Por favor, escute isso sem me recriminar. Eu não posso fazer isso, eu não quero." (Renata, E. C.)

Interessante notar a expressão "ser humano" e "sujeito" nessa fala, expressando uma concepção coerente com o quadro da intervenção. Sem deixar de constituir um dilema para a profissional, esse caso trouxe-lhe a possibilidade de compreender e de compartilhar com o usuário sentidos para o viver que fogem aos padrões normalmente estipulados e almejados pelos profissionais de saúde.

\section{Benefícios aos Usuários}

De modo geral, as entrevistadas perceberam diversas repercussões para o tratamento trazidas pela intervenção. A melhora na convivência com o tratamento pôde ser constatada em diversos casos:

tem vários depoimentos . . . de gente que fala de mudanças: "Ah! Eu não conseguia engolir o comprimido e agora eu engulo", "Eu não podia tomar o comprimido fora de casa com medo de passar mal e agora eu tomo". (Renata, E. I.)

Observaram que os ganhos obtidos foram desde uma maior apropriação das formas de manejo do tratamento, até transformações no contexto de vida dos usuários, como no exemplo de uma pessoa que dizia atrasar frequentemente a tomada dos remédios por conta de sua agitada rotina de trabalho. Os encontros apoiaram sua decisão de pedir demissão do emprego para cuidar de si mesma e de sua saúde:

Não me recordo se foi no segundo ou no terceiro [encontro] que ela chegou aqui e falou ". . . Eu tomei uma decisão. Eu pedi demissão do meu emprego". . . Ela tem uma pensão do marido ... o filho já é formado .. tem casa própria . . tem uma vida relativamente . . estável, acharam por bem que ela realmente poderia pedir demissão para se cuidar. ... Ela fez um check-up ... passou por uma série de profissionais daqui . . . marcou otorrino . . ortopedia . . psicologia ... Indo aos encontros ela percebeu que ela não estava olhando para si própria e isso ela realmente conseguiu. Eu acho que a percepção de si mesma veio à tona e ela começou a se cuidar. (Joana, E. I.)

A ampliação do acesso aos recursos ofertados pela instituição foi outra importante decorrência da intervenção valorizada pelas profissionais. As entrevistadas consideraram que, "do ponto de vista da relação desses pacientes com a instituição, a intervenção trouxe uma nova possibilidade" (Renata, E. I.), promovendo novas formas de apropriação dos espaços de Cuidado. O caráter dialógico e horizontal da relação estabelecida durante os encontros mostrou-se fundamental para situar o usuário como sujeito de direitos, co-responsável pelos rumos de seu próprio tratamento. As entrevistadas consideraram que essa interação diferenciou-se da relação de autoridade em geral estabelecida com o médico, na qual o usuário dificilmente questiona a prescrição do tratamento em busca de melhor adaptá-lo à sua vida cotidiana:

eu acho que isso também faz parte do tratamento .. . se a gente tiver conseguido quebrar um pouquinho na cabeça deles 
[participantes] essa questão da autoridade, se eles conseguirem a partir disso entrar de uma forma um pouquinho mais tranquila, no sentido de se colocar e conversar na consulta . . . se vendo com direitos . . . se vendo com um espaço que é dele, que não é daquele profissional, que é dele, é a vida dele, é ele quem está em jogo. (Renata, E. I.) Segundo as profissionais, a pesquisa também evidenciou algumas relações já "desgastadas" (Renata, E. I.) entre médicos e usuários: eu acho que às vezes é um cansaço, não tem mais o que dar, a pessoa [o profissional] está exaurida e esse paciente também, naquela relação, ficam os dois: "Está tudo bem" / "Está tudo bem"... são relações que estão mortas. (Renata, E. I.)

A intervenção permitiu resgatar casos em que os profissionais pareciam ter deixado de acreditar na possibilidade de ocorrerem avanços: "eu senti na fala dos usuários que os médicos . . tem uma grande expectativa em relação à pesquisa, porque o paciente que está aqui . . é aquele que ele também tem dificuldade no consultório" (Marina, E. I.).

Em relação ao papel da instituição, as entrevistadas ressaltaram a importância da oferta de um espaço enfocando o tema da adesão. Na visão das profissionais, o simples fato de os participantes serem contatados pela pesquisa no serviço que sentiram ser um cuidado institucional - foi capaz de promover transformações na forma de lidarem com o tratamento. Ressaltaram, contudo, a necessidade de se oferecer apoio de forma contínua, de modo a promover a manutenção das conquistas em longo prazo, dado o caráter dinâmico da adesão ao tratamento. Este aspecto foi ilustrado por uma entrevistada ao imaginar a fala dos usuários:

Agora estou bem, não vou tomar o remédio. Agora estou doente, então eu vou começar a tomar o remédio. Ah! Mas agora eu tenho muita coisa para fazer da minha vida, então eu não estou conseguindo tomar o remédio direito. (Marina, E. I.)

A intervenção ressaltou também, segundo as entrevistadas, a necessidade de se dirigir ações específicas àqueles usuários que se consideram aderentes, ou que não faltam às consultas, mas que, no entanto, não obtêm melhoras nos resultados clínicos do tratamento - condições que muitas vezes passam despercebidas pela instituição:

Eu acho que a gente trabalha muito com adesão com aquele paciente que verbaliza: "Não, eu não tomo remédio. Eu não quero tomar remédio". . . . Agora, esse paciente que fala: . . . "Eu tô tomando" ... A gente não investe. (Marina, E. I.)

\section{Implantação nos Serviços}

As entrevistadas acreditam na viabilidade da implantação da intervenção em outros serviços da rede pública, mas apontaram que essas ações precisam estar inseridas dentro de um fluxo de trabalho na instituição para garantir o envolvimento dos profissionais nesse processo e o apoio da gestão: "não adianta . . ensinar os profissionais a fazerem uma coisa, se o serviço não está se modificando na direção da melhora da sua qualidade" (Renata, E. C.). A introdução deste modelo de intervenção no serviço desafiaria especialmente a fragmentação do tratamento entre as diferentes especialidades, como ilustra a fala de um dos participantes durante os encontros, citada pela profissional: "Com o médico eu trato de uma coisa, com o psicólogo eu trato de outra, e aqui foi o único lugar que eu juntei as duas" (Renata, E. C.).

As entrevistadas destacaram o caráter interdisciplinar da intervenção porque, além de propor um diálogo entre os diferentes saberes, a ACCA traz ferramentas que podem ser utilizadas por todas as categorias profissionais - aspectos estes nem sempre valorizados na rotina de trabalho nos serviços:

a assistente social e o psicólogo têm mais dificuldade em se interessar por estudar a questão dos medicamentos. Um médico, por sua vez, tem resistência em estudar aquilo que não é exatamente a condução clínica do caso. A enfermeira tem uma visão pragmática das coisas, então ela tem dificuldade de incluir no seu raciocínio, muitas vezes, as questões sociais e psicológicas, então cada um valoriza o seu núcleo. (Renata, E. C.) Ressaltaram a necessidade de se trabalhar, 
em uma futura implantação, junto à "equipe toda . . incluindo na capacitação a percepção de onde está localizada essa atividade, que ela serve ao paciente, ela não serve ao profissional. . . . identificar a adesão como um campo inter [disciplinar]" (Renata, E. C.).

Por fim, as profissionais valorizaram o instrumento de registro preenchido conjuntamente, caracterizando-o como uma estratégia útil para o compartilhamento das questões trabalhadas nos atendimentos, não apenas entre profissional e usuário, mas também entre a equipe de profissionais responsáveis pelo seu Cuidado:

Qualquer pessoa [profissional] que vai atender aquela pessoa [usuário], ela vai de posse daquele material, vai enriquecer. E se combinado com o paciente que aquilo vai poder fazer parte do prontuário, todo mundo pode acessar . . . no fim, aquela dificuldade fica sendo compartilhada, conversada com um monte de gente . . da equipe que atende aquela pessoa. Quer dizer, você faz a intervenção, mas eu também posso falar sobre aquele assunto. (Renata, E. C.)

\section{Conclusões}

Em síntese, do ponto de vista das profissionais que conduziram a intervenção, a ACCA mostrou-se uma abordagem factível no contexto do SUS; possível de ser reproduzida por profissionais de diferentes categorias; capaz de beneficiar a convivência das pessoas com seu tratamento; e com o potencial de inovar a atuação profissional no plano da assistência às pessoas vivendo com HIV. Os depoimentos das profissionais chamaram atenção, também, para aspectos da proposta de intervenção a serem revistos e/ou enfatizados em uma futura implantação da ACCA.

Dentre as contribuições dessa abordagem para a prática, as profissionais destacaram as ideias de priorização da perspectiva do usuário e de aprofundamento da conversa em torno de sua vida cotidiana. A partir dessa proposição, a relação de cada pessoa com seu tratamento pôde ser co-compreendida de modo singular e encarnado em seus diversos contextos intersubjetivos, levando à ruptura com pré-concepções e estereótipos a respeito de supostos perfis do "paciente tipo-aderente" ou "tipo-não-aderente". A noção de conveniência e de participação dos usuários na escolha dos caminhos para seu autocuidado permitiu, ainda, a construção de novos parâmetros de sucesso para a atuação profissional.

O modo de interação dialógica que amplia a cena da tomada e do atendimento para o contexto social e programático com os usuários permitiu situá-los enquanto sujeitos de direitos, valorizando esse discurso que tem evidentes repercussões programáticas e sociais. Diversos benefícios programáticos para o tratamento foram indicados pelas entrevistadas: a possibilidade de um melhor aproveitamento dos serviços ofertados pela instituição; as reflexões em torno da necessidade de os serviços organizarem espaços contínuos para se trabalhar o tema da adesão, acompanhando todos aqueles que não apresentam bons resultados clínicos do tratamento; o enfoque interdisciplinar. $\mathrm{O}$ estudo confirmou a expectativa e o pressuposto do quadro de que a implantação em outros serviços exigirá um trabalho prévio junto à instituição e aos profissionais para promover a abertura necessária para esta abordagem, como discutiram as profissionais entrevistadas.

Especificamente em relação ao manejo da intervenção, as maiores dificuldades citadas pelas profissionais referiram-se a situações em que identificaram pouca disponibilidade do usuário para trabalhar expressando seu momento e contexto de vida, ou sua trajetória como pessoa vivendo com HIV. Esses mesmos aspectos dificultaram particularmente a exploração e decodificação de cenas de tomada da medicação. Quando o recurso das cenas pareceu fazer sentido para o usuário, essa metodologia permitiu a ampliação da compreensão das situações trabalhadas e o levantamento de novas alternativas para lidar com o cotidiano do tratamento.

De modo geral, podemos dizer que a intervenção possibilita situar o profissional e o usuário enquanto sujeitos da intervenção, a partir do reconhecimento de que o usuário, tanto quanto o profissional, é detentor de um saber - sobre seu contexto de vida, seu cotidiano, seus recursos 
pessoais, sociais e institucionais para lidar com o seu tratamento - e que, em torno do que ele sabe (contextos) e pode (recursos) é que serão construídos caminhos possíveis para uma melhor convivência com o tratamento (Paiva, 2002).

Nota-se que, na abordagem da ACCA, a construção do vínculo e do diálogo entre profissional e usuário é ponto fundamental para o sucesso da intervenção. Entendemos que, em cada atendimento, é preciso refletir sobre as dificuldades percebidas para o estabelecimento desse diálogo e da interação, de modo a não responsabilizarmos os usuários individualmente pelos fracassos obtidos. Esse é um ponto a ser valorizado em uma futura implantação da intervenção.

Ressaltamos que uma das diferenças mais importantes, quando se discutem os limites e potencialidades da ACCA, é o fato de depender da singular interação que se estabelece entre aquele usuário e o profissional, bem como do contexto programático onde se desenvolverá. Não se pode, portanto, generalizar determinados contextos e situações como características que estariam a priori associadas com o sucesso ou o fracasso da intervenção. Em relação ao recurso das cenas, um dos recursos considerados mais interessantes e renovadores da prática segundo as experiências acumuladas no campo da prevenção, a viabilidade da metodologia das cenas têm se mostrado nos mais diversos contextos sociais, tais como junto a populações caiçaras (Bellenzani, Blessa, \& Paiva, 2008; A. O. Santos \& Paiva, 2007), comunidades ribeirinhas na Amazônia (Benzaken, Garcia, Sardinha, Pedrosa, \& Paiva, 2007), jovens religiosos (Paiva, Garcia, et al., 2010) e com os profissionais responsáveis pela atenção à sua saúde. Entendemos, portanto, que é possível em uma futura implantação da intervenção aprofundar a discussão em torno das dificuldades percebidas pelas profissionais e pensar caminhos para aprimorar o diálogo com os usuários.

De modo geral, consideramos que essa experiência reafirma a importância do estabelecimento de protocolos de intervenção que orientem a prática - o que não deve se confundir, no entanto, com uma padronização rígida das ações. Ao contrário, esta proposta visa estimular justa- mente a criatividade dos profissionais no manejo dos recursos disponíveis, de forma a adaptá-los às especificidades da relação estabelecida com cada usuário, sem desconsiderar também as possibilidades do contexto particular de cada serviço. A formação sobre as estratégias e concepções da ACCA, por exemplo, foi proporcionada não apenas pelas atividades de capacitação, mas aprimorada pela supervisão, que interagiu com o saber prático das profissionais, como aliás acontece em todas as outras abordagens. Uma educação dialógica e continuada de profissionais para permitir um maior aprofundamento na apropriação desta ou de outras abordagens que visam inovar a atenção no âmbito do SUS será sempre produtiva da sua maior qualidade.

Reiteramos que o contexto de pesquisa e, portanto, o ambiente necessariamente mais controlado dentro do qual a intervenção foi realizada, ainda que permita o reconhecimento de diversas potencialidades e aprimoramentos necessários à ACCA, impõe inevitáveis limites à nossa análise, impossibilitando-nos de conhecer quais outros aspectos poderiam decorrer de uma implantação efetiva da intervenção na rotina dos serviços. Este estudo pode apenas levantar hipóteses a respeito dos possíveis benefícios da adoção da ACCA no cotidiano dos serviços e desta formação de profissionais de saúde. Hipóteses que, por referirem-se ao que pudemos apreender do ponto de vista das profissionais, serão complementadas pela análise das entrevistas realizadas com os usuários participantes, bem como da gravação dos encontros. Uma análise panorâmica posterior permitirá uma maior compreensão a respeito deste modelo de intervenção.

Finalizando, destacamos que a reflexão crítica suscitada pelas entrevistas com as profissionais inclui essa abordagem no campo das abordagens que propõem a substituição da noção de adesão por ideias que expressem "colaboração" (Nemes, Santa-Helena, Caraciolo, \& Basso, 2009), "autonomia" (Williams, Rodin, Ryan, Grolnick, \& Deci, 1998), "empoderamento" (Feste \& Anderson, 1995) e, especialmente, "concordância" (Royal Pharmaceutical Society of Great Britain, 1997). Nessa mesma direção estão as hipóteses de que a valorização pelo pro- 
fissional, no encontro com o usuário, da vida cotidiana e de suas dinâmicas intersubjetivas pode enriquecer a comunicação entre ambos; que a compreensão das conveniências do tratamento, tanto por parte do profissional quanto do usuário, pode levar a arranjos mais viáveis e compatíveis com o contexto e o dia a dia da pessoa em tratamento; que o compartilhamento entre profissional e usuário da responsabilidade pelo Cuidar é fundamental para caminharmos em direção à incorporação do referencial dos direitos que tem sido valorizado nas práticas de atenção à saúde (Gruskin \& Tarantola, 2008); e, por fim, que a possibilidade de os usuários e profissionais dialogarem nos termos dos usuários pode contribuir para a superação da paralisia que tantas vezes afeta a ambos com a sensação de que não restam caminhos para a (re)construção conjunta de projetos de felicidade.

\section{Referências}

Amico, K. R., Harman, J. J., \& Johnson, B. T. (2006). Efficacy of antiretroviral therapy adherence interventions: A research synthesis of trials, 1996 to 2004. Journal of Acquired Immune Deficiency Syndromes, 41(3), 285-297.

Ayres, J. R. C. M. (2001). Sujeito, intersubjetividade e práticas de saúde. Ciência \& Saúde Coletiva, 6(1), 63-72.

Ayres, J. R. C. M. (2004). Cuidado e reconstrução das práticas de saúde. Interface - Comunicação, Saúde e Educação, 8(14), 73-92.

Ayres, J. R. C. M., Calazans, G., Saletti, H. C., Filho, \& França, I., Jr. (2006). Risco, vulnerabilidade e práticas de prevenção e promoção da saúde. In G. W. S. Campos, M. C. S. Minayo, M. Akerman, M. Drummond Jr., \& Y. M. Carvalho (Orgs.), Tratado de Saúde Coletiva (pp. 375417). São Paulo, SP: Hucitec.

Ayres, J. R. C. M., Paiva, V. S. F., \& França, I., Jr. (2011). From Natural History of Disease to Vulnerability: Changing concepts and practices in contemporary public health. In R. Parker \& M. Sommers (Eds.), Routledge handbook of global public health (pp. 98-107). New York: Routledge.

Ayres, J. R. C. M., Paiva, V. S. F., \& França, I., Jr. (2012). Conceitos e práticas de prevenção: Da história natural da doença ao quadro da vulnerabilidade e direitos humanos. In V. S. F. Paiva, J. R. C. M. Ayres, \& C. M. Buchalla (Orgs.), Vulnerabilidade e direitos humanos: Prevenção e promoção da saúde (Vol. 1, pp. 71-94). Curitiba, PR: Juruá.

Bãban, A., \& Crãciun, C. (2007). Changing healthrisk behaviors: A review of theory and evidence-based interventions in health psychology. Journal of Cognitive and Behavioral Psychotherapies, 7(1), 45-67.

Basso, C. R. (2010). Avaliação da efetividade de uma intervenção psicossocial para melhorar a adesão do paciente à terapia antirretroviral da AIDS: Ensaio controlado aleatório utilizando monitoramento eletrônico (Tese de doutorado, Departamento de Medicina Preventiva, Faculdade de Medicina, Universidade de São Paulo, SP, Brasil).

Basso, C. R., Santa-Helena, E. T., Caraciolo, J. M. M., Paiva, V. S. F., \& Nemes, M. I. B. (2012). Exploring ART intake scenes in a human rightsbased intervention to improve adherence: A randomized controlled trial. AIDS and Behavior. doi: 10.1007/s10461-012-0175-4. Retrieved May 15, 2012, from http://www.springerlink. com/content/a4860529p1g13127/

Bellenzani, R., Blessa, C. R. B., \& Paiva, V. S. F. (2008). Scripts in scene: HIV and sexual market in the context of tourism. Psicologia em Estudo, 13(4), 653-662.

Benzaken, A. S., Garcia, E. G., Sardinha, J. C. G., Pedrosa, V. L., \& Paiva, V. S. F. (2007). Community-based intervention to control STD/AIDS in the Amazon region, Brazil. Revista de Saúde Pública, 41(Supl. 2), 118-126.

Berger, P. L., \& Luckmann, T. (1987). A construção social da realidade: Tratado de Sociologia do Conhecimento (7. ed.). Petrópolis, RJ: Vozes.

Berkman, A., Garcia J., Munoz-Laboy, M., Paiva, V. S. F., \& Parker, R. (2005). A critical analysis of the Brazilian response to HIV/AIDS: Lessons for controlling and mitigating the epidemic in developing countries. American Journal Public Health, 95(7), 1162-1172.

Caraciolo, J. M. M. (2010). Caracterização das atividades para melhoria da adesão à TARV em serviços de saúde do SUS no estado de São Paulo (Dissertação de mestrado, Departamento de Medicina Preventiva, Faculdade de Medicina, Universidade de São Paulo, SP, Brasil). 
Caraciolo, J. M. M., Santa-Helena, E. T., Basso, C. R., Souza, R. A., Silva, M. H., Adão, V. M., ...Nemes, M. I. B. (2009). Atividades para melhoria da adesão à TARV em serviços de saúde do SUS no estado de São Paulo, 2007. Saúde e Sociedade, 18(Supl. 2), 79-83.

Dulmen, S., van., Sluijs, E., Dijk, L., van, Ridder, D., Heerdink, R., \& Bensing, J. (2007). Patient adherence to medical treatment: A review of reviews. BMC Health Services Research, 7, 55-67.

Feste, C., \& Anderson, R. M. (1995). Empowerment: From philosophy to practice. Patient Education and Counseling, 26(1), 139-144.

Freire, P. (1987). Pedagogia do oprimido (17. ed.). Rio de Janeiro, RJ: Paz e Terra.

Gagnon, J., \& Parker, R. (1995). Conceiving sexuality: Approaches to sex research in a postmodern world. New York: Routledge.

Glanz, K., Lewis, F. M., \& Rimer, B. K. (Eds.). (2002). Health behavior and health education: Theory, research and practice ( $3^{\text {rd }}$ ed.). San Francisco, CA: Jossey-Bass.

Goffman, E. (1975). A representação do eu na vida cotidiana. Petrópolis, RJ: Vozes.

Goffman, E. (1980). Estigma: Notas sobre a manipulação da identidade deteriorada (3. ed.). Rio de Janeiro, RJ: Zahar.

Gruskin, S., \& Tarantola, D. (2008). Universal access to HIV prevention, treatment and care: Assessing the inclusion of human rights in international and national strategic plans. AIDS, 22(Suppl. 2), S123-S132.

Jung, C. G. (1985). Fundamentos de psicologia analítica (3. ed.). Petrópolis, RJ: Vozes.

Kalichman, A., \& Diniz, S. (2009). AIDS treatment in Brazil: What kind of evidence do we need? Lancet, 374(969), 1066.

Mann, J., \& Tarantola, D. J. M. (1996). AIDS in the world II. New York: Oxford University Press.

Melchior, R., Nemes, M. I. B., Alencar, T. M. D., \& Buchalla, C. M. (2007). Desafios da adesão ao tratamento de pessoas vivendo com HIV/Aids no Brasil. Revista de Saúde Pública, 41(Supl. 2), 87-93.

Munro, S., Lewin, S., Swart, T., \& Volmink, J. (2007). A review of health behaviour theories: How useful are these for developing interventions to promote long-term medication adher- ence for TB and HIV/AIDS? BMC Health Services Research, 7, 104-119.

Nemes, M. I. B. (2009). Desenvolvimento da linha de pesquisa Qualiaids (Tese de livre docência, Departamento de Medicina Preventiva, Faculdade de Medicina, Universidade de São Paulo, SP, Brasil).

Nemes, M. I. B., Castanheira, E. R. L., Santa-Helena, E. T., Melchior, R., Caraciolo, J. M. M., Basso, C. R., ...Ferraz, D. A. S. (2009). Adesão ao tratamento, acesso e qualidade da assistência em aids no Brasil. Revista da Associação Médica Brasileira, 55(2), 207-212.

Nemes, M. I. B., Equipe Qualiaids, \& CRT-DST/ AIDS-SP (Coords.). (2009). Avaliação de tecnologias para melhoria da adesão do paciente ao tratamento antirretroviral da Aids (Relatório técnico PP-SUS 2006/2007, FAPESP Processo No 2006/61277-6). São Paulo, SP: Fundação de Amparo à Pesquisa do Estado de São Paulo.

Nemes, M. I. B., Santa-Helena, E. T., Caraciolo, J. M. M., \& Basso, C. R. (2009). Assessing patient adherence to chronic diseases treatment: Differentiating between epidemiological and clinical approaches. Cadernos de Saúde Pública, 25(Suppl. 3), s392-s400.

Paiva, V. S. F. (2002). Sem mágicas soluções: A prevenção e o cuidado em HIV/AIDS e o processo de emancipação psicossocial. Interface - Comunicação, Saúde e Educação, 6(11), 25-38.

Paiva, V. S. F. (2005). Analysing sexual experiences through 'scenes': A framework for the evaluation of sexuality education. Sex Education, 5(4), 345-359.

Paiva, V. S. F. (2006). Analisando cenas e sexualidades: A promoção da saúde na perspectiva dos direitos humanos. In C. F. Cáceres, G. Careaga, T. Frasca, \& M. Pecheny (Orgs.), Sexualidad, estigma y derechos humanos: desafios para el acesso a la salud en América Latina (pp. 23-52). Lima, Peru: Facultad de Salud Pública y Administración Carlos Vidal Layseca, Universidad Peruana Cayetano Heredia.

Paiva, V. S. F. (2007). Gendered scripts and the sexual scene: Promoting sexual subjects among Brazilian teenagers. In R. Parker \& P. Aggleton (Eds.), Culture, society and sexuality: A reader ( $2^{\text {nd }}$ ed., pp. 427-442). New York: Routledge.

Paiva, V. S. F. (2008). A psicologia redescobrirá a sexualidade? Psicologia em Estudo, 13(4), 641-651. 
Paiva, V. S. F. (2009). Prevenção PositHIVa? A abordagem psicossocial, emancipação e vulnerabilidade. In J. C. Raxach, I. Maksud, C. Pimenta, \& V. Terto Jr. (Orgs.), Prevenção positHIVa: Estado da arte: Vol. 8. Políticas públicas (pp. 33-49). Rio de Janeiro, RJ: Associação Brasileira Interdisciplinar de Aids.

Paiva, V. S. F. (2012a). Cenas da vida cotidiana: Metodologia para compreender e reduzir a vulnerabilidade na perspectiva dos direitos humanos. In V. S. F. Paiva, J. R. C. M. Ayres, \& C. M. Buchalla (Orgs.), Vulnerabilidade e direitos humanos: Prevenção e promoção da saúde (Vol. 1, pp. 165-207). Curitiba, PR: Juruá.

Paiva, V. S. F. (2012b). A dimensão psicossocial do Cuidado. In A. Segurado, G. Calazans, \& V. S. F. Paiva (Orgs.), Vulnerabilidade e direitos humanos: Prevenção e promoção da saúde (Vol. 2, pp. 41-71). Curitiba, PR: Juruá.

Paiva, V. S. F., Ayres, J. R. C. M., \& Gruskin, S. (2010). Being young and living with HIV: The double neglect of sexual citizenship. In P. Aggleton \& R. Parker (Eds.), Routledge handbook of sexuality, health and rights (pp. 422-430). New York: Routledge.

Paiva, V. S. F., Garcia, J., Rios, L. F., Santos, A. O., Terto, V., Jr., \& Munõz-Laboy, M. (2010). Religious communities and HIV prevention: An intervention study using a human rights-based approach. Global Public Health, 5(3), 280-294.

Parker, R., \& Aggleton, P. (1999). Culture, society and sexuality: A reader. New York: Routledge.

Parker, R., \& Aggleton, P. (2001). Estigma, discriminação e AIDS: Coleção ABIA: Vol. 1. Cidadania e direitos. Rio de Janeiro, RJ: Associação Brasileira Interdisciplinar de Aids.

Royal Pharmaceutical Society of Great Britain. (1997). From compliance to concordance: Toward shared goals in medicine taking. London: Author.

Rueda, S., Park-Wyllie, L. Y., Bayoumi, A. M., Tynan, A. M., Antoniou, T. A., Rourke, S. B., \& Glazier, R. H. (2006). Patient support and education for promoting adherence to highly active antiretroviral therapy for HIV/AIDS. Cochrane Database of Systematic Reviews, 3, CD001442. Retrieved March 31, 2012, from http://www. mrw.interscience.wiley.com/cochrane/clsysrev/ articles/CD001442/frame.html
Santos, A. O., \& Paiva, V. S. F. (2007). Vulnerabilidade ao HIV: Turismo e uso de álcool e outras drogas. Revista de Saúde Pública, 41(Supl. 2), 80-86.

Santos, M. A. (2010). Análise crítica de uma intervenção para melhoria da adesão do paciente vivendo com AIDS à terapia antirretroviral (Dissertação de mestrado, Departamento de Psiclogia Social, Instituto de Psicologia, Universidade de São Paulo, SP, Brasil).

Sato, L. (2005). Apresentação. In A. M. Rodrigues (Org.), Individuo, grupo e sociedade: Estudos de Psicologia Social (pp. 11-15). São Paulo, SP: Editora da Universidade de São Paulo.

Simon, W., \& Gagnon, J. H. (1984). Sexual scripts. Society, 22(1), 53-60.

Simoni, J. M., Frick, P. A., Pantalone, D. W., \& Turner, B. J. (2003). Antiretroviral adherence interventions: A review of current literature and ongoing studies. Topics in HIV Medicine, 11(6), 185-198.

Simoni, J. M., Pearson, C. R., Pantalone, D. W., Marks, G., \& Crepaz, N. (2006). Efficacy of interventions in improving highly active antiretroviral therapy adherence and HIV-1 RNA viral load. A meta-analytic review of randomized controlled trials. Journal of Acquired Immune Deficiency Syndromes, 43(Suppl. 1), S23-S35.

Teixeira, P. R., Paiva, V. S. F., \& Shimma, E. (Orgs.). (2000). Tá difícil de engolir? Experiências de adesão ao tratamento anti-retroviral em São Paulo. São Paulo, SP: Núcleo de Estudos para a Prevenção da Aids, Universidade de São Paulo.

Williams, G. C., Rodin, G. C., Ryan, R. M., Grolnick, W. S., \& Deci, E. L. (1998). Autonomous regulation and long-term medication adherence in adult outpatients. Health Psychology, 17(3), 269-276. 